\title{
Surrogate pregnancy: a guide for Canadian prenatal health care providers
}

\section{Dan R. Reilly}

$\infty \quad$ See related article page 479

\section{ABSTRACT}

Providing health care for a woman with a surrogate pregnancy involves unique challenges. Although the ethical debate surrounding surrogacy continues, Canada has banned commercial, but not altruistic, surrogacy. In the event of a custody dispute between a surrogate mother and the individual(s) intending to parent the child, it is unclear how Canadian courts would rule. The prenatal health care provider must take extra care to protect the autonomy and privacy rights of the surrogate. There is limited evidence about the medical and psychological risks ofsurrogacy. Whether theoretical concerns about these risks are clinically relevant remains unknown. In the face of these uncertainties, the prenatal health care provider should have a low threshold for seeking obstetrical, social work, ethical and legal support.

CMAJ 2007;176(4):483-5

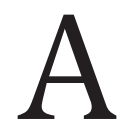

fter a busy morning in the office, you have an appointment with a new prenatal patient. This gravida 3 , para 2 woman is at 6 weeks' gestation. There are 3 people waiting in the examination room: the patient and couple whose egg and sperm were used to create the embryo being gestated by the patient. Each person has questions about prenatal care and wishes to be involved in any decisions that need to be made.

It is unknown how common surrogate pregnancy is in Canada. Surrogacy is not a medical condition that has a rate or prevalence that can be tracked, but rather it is a social arrangement or agreement that is private in nature. ${ }^{1}$ Surrogacy can be either traditional or gestational. A traditional surrogate mother contributes an egg and is thus genetically related to the resulting child. This form of surrogacy is also called "straight," "natural" or "partial" surrogacy. In contrast, gesta" tional surrogacy is also known as "full," "host," "in vitro fertilization" surrogacy or "gestational carrier pregnancy." The use of in vitro fertilization in gestational surrogacy allows the woman intending to parent the child to be genetically related to the child. The person or persons intending to parent the child that results from the surrogate pregnancy are referred to as the commissioner(s), or as the commissioning individual or couple. Either form of surrogacy can be commercial (the surrogate is compensated by the commissioner[s]) or altruistic (the surrogate chooses to carry the child for reasons other than financial gain).

\section{The ethics of surrogacy}

There is an ongoing debate in the ethics literature regarding commercial surrogacy. Those in favour of it appeal to libertarian ethics that value free choice (to enter contracts) and personal autonomy (to do what you choose with your body) 2 $^{2,3}$ and claim a right to self-fulfillment (through raising your own child) and privacy. ${ }^{4}$ When a ban on commercial surrogacy is considered, those in favour of commercial surrogacy raise the spectre of government or other paternalistic social institutions interfering with personal rights without adequate cause. ${ }^{3,5,6}$ In contrast, people with a communitarian view argue that the moral nature of child-bearing and the parent-child relationship suffers when commercialized, that children cannot be seen as commodities and that the duty of parent to child is inalienable and cannot be sold or abandoned. ${ }^{4,7,8}$ Opponents of commercial surrogacy compare it to prostitution and slavery. ${ }^{7,8}$ The Royal Commission on New Reproductive Technologies found a similar range of opinions when Canadians were surveyed in $1993 .^{9}$

\section{The law and surrogacy}

Differing ethical and social opinions have led to legal frameworks that vary between jurisdictions. In Israel, commercial surrogacy is legal, yet familial and altruistic surrogacy are banned because of religious reasons related to incest and adultery. ${ }^{7}$ In the United States, surrogacy is permitted in several states with different amounts of weight given to surrogacy contracts; however, a large number of states have banned all forms of surrogacy. The Australian Capital Territory and the United Kingdom both permit altruistic, but not commercial, surrogacy. Indeed, in the United Kingdom volunteer organizations will help commissioner(s) who cannot find a surrogate mother. ${ }^{7,10}$

In Canada, before March 2004 surrogacy was unregulated. The Canadian Medical Association recommended that a potential surrogate be chosen who had previously given birth so 
that she would be better able to give informed consent. ${ }^{11} \mathrm{~Pa}-$ tients could choose to pay a service to find a commercial surrogate, or a family member or friend could choose to be an altruistic surrogate.

The Assisted Human Reproduction Act was granted royal assent in March 2004, giving Canada a legal framework to manage surrogate pregnancy. The act has jurisdiction across Canada. However, certain sections of the act may not apply in a particular province if both the federal minister of health and the provincial government agree that the provincial legislation is equivalent to those sections. The act's jurisdiction in Quebec is a question currently before the Quebec Court of Appeal. ${ }^{12}$

This act makes it a criminal offense to pay or offer to pay a woman to act as a surrogate; to pay or offer to pay a person to arrange for the services of a surrogate; to advertise payment for surrogacy or the arrangement of surrogacy; or to assist or counsel any person under 2I years of age to become a surrogate. In addition, reimbursing a surrogate for her expenditures during gestation became a controlled act and now requires a licence and compliance with regulations that are still pending. For example, these expenditures could include wages lost if a physician certifies that working threatens the surrogate's health or the health of the embryo or fetus. ${ }^{13}$

The Assisted Human Reproduction Act does not address whether surrogacy agreements are valid, and Canadian case law has yet to address the issues of a custody dispute between a surrogate mother and commissioner(s). The Quebec Civil Code explicitly states that surrogacy agreements are null and have no legal standing. ${ }^{14}$ Jurisdictions in other Commonwealth nations and in the United States have ruled in various ways on such conflicts. In general, judges have chosen to ignore surrogacy agreements for public policy reasons and have ruled in the best interests of the child. ${ }^{1}$ Ethicists also agree in general that the child's best interests trump any other considerations. ${ }^{6}$ Canadian judges may or may not choose to be guided by previous rulings or by dominant ethical opinion. Until there has been a Canadian case or relevant provincial legislation is passed, there is no guarantee of outcome if the surrogate mother refuses to part with the child after birth or if one or both commissioners refuse to accept a child who is born with a disability.

\section{The law and care of the surrogate}

Canadian law is clear about who makes health care decisions during a woman's pregnancy. The Canadian Charter of Rights and Freedoms provides all women (pregnant or not) with the right to integrity of both body and mind and the right to the autonomy to make personal decisions. ${ }^{1}$ The common law views the gestating fetus as part of the woman's body. ${ }^{15,16}$ The right to autonomy granted by the charter with respect to decisions that affect a person's body is based on ethical respect for the individual and is in agreement with case law, provincial legislation and the medical codes of ethics that require informed consent for medical procedures. The health care provider must obtain informed consent from the surrogate and must respect her right to accept or refuse medical procedures.
Although a surrogate is free to consider the wishes of the commissioner(s), it is unclear whether a surrogate could voluntarily surrender her autonomy for making medical decisions to the commissioner(s). A patient may choose to allow another person to make medical decisions on his or her behalf, but that person must still act in the best interest of the patient. It is unclear, however, whether the commissioner(s) would be able to act in the surrogate's best interests if a conflict of interest were to develop between the surrogate and the fetus. Indeed, ethical and legal opinions should be sought if a surrogate wishes to allow the commissioner(s) to make medical decisions on her behalf.

When seeking informed consent from a surrogate, the health care provider will need to take special care to ensure that the surrogate is not being coerced by the commissioner(s). Since commercial surrogacy is illegal in Canada, financial coercion should not be an issue. However, if the surrogate and the commissioner are family members or are close social relations, then coercion may be subtle. ${ }^{17}$ Thus, the health care provider will need to have conversations alone with the surrogate. For example, in the case presented at the beginning of this article, the prenatal physical examination would be a good time to speak privately with the surrogate. As well, psychology or social work counsellors may need to become involved to ensure that the surrogate is making truly autonomous decisions.

The health care provider should avoid the possibility of a conflict of interest by caring for either the surrogate or the commissioner(s), but not both. The surrogacy process can be compared to an organ transplant with a live organ donor, because both the surrogate and commissioning mother may face medical and psychological risks and their needs may come into conflict. ${ }^{7}$ To avoid conflicts, a different physician should care for each woman during the in vitro fertilization process, and the physician or midwife caring for the surrogate during pregnancy should have no duty of care or other responsibilities for the commissioner(s) because each health care provider must be free to pursue the best interest of the patient.

Just as the surrogate retains complete control to make medical decisions, she also retains the right to confidentiality. She alone has the right to determine what information about the pregnancy the health care provider can share with the commissioner(s).

After the surrogate gives birth, there is a new patient who has the right to have health care provided in his or her best interests. There may be a dispute between the surrogate and the commissioner(s) about who speaks for and cares for the child. Given the legal uncertainties surrounding surrogacy, a health care provider who encounters such a dispute would be wise to quickly seek social work, ethical and legal support.

\section{Prenatal care of the surrogate}

The literature regarding the medical risks associated with surrogate pregnancy is limited to a few case series. It remains to be determined if the obstetric risks are the same as those for any other pregnancy derived by in vitro fertilization with 
the same number of fetuses. Most case series report no increase in adverse events related to surrogate pregnancy. ${ }^{10,18-22}$ However, in a recent report, 2 of 9 surrogate mothers underwent postpartum hysterectomy: after a delivery of triplets with placenta accreta and after uterine rupture that occurred during delivery of a macrosomic infant. ${ }^{23}$ The limited amount of evidence about the risks associated with surrogate pregnancy has 2 implications: (a) health care providers should have a high index of suspicion for complications and a low threshold for investigations and referral to higher levels of care; and (b) if complications occur, health care providers should report the complications to the centre that initiated the pregnancy so that surrogacy outcomes can be tracked and a better evidence base can be built.

Ethics and psychology literature, as well as medical expert opinion, raise many theoretical concerns about the emotional well-being of surrogates and commissioner(s), especially after delivery of the child., ${ }^{724-27}$ These sources recommend that surrogate pregnancy be treated as a high-risk psychological experience for all involved. In addition, it is recommended that surrogates receive professional counseling during and after the pregnancy. Case series that have explored the experiences of surrogates and commissioner(s) have not noted any substantial psychological issues. ${ }^{10,21,22,28-32}$ Surrogates did not experience a higher than average postpartum depression rate..$^{10,21,22}$ The evidence is limited, but perhaps these theoretical concerns are not clinically relevant. An alternative explanation for the discrepancy between expert opinion and clinical experience is that thorough counselling before conception reduces psychological risk. If counselling is easily accessible, making it routine practice does not appear to cause harm. If access to psychological services is limited in the centre where a surrogate chooses to be cared for and to give birth, it would be prudent for the health care provider to closely follow the surrogate's emotional health during and after pregnancy.

\section{Conclusion}

In the opening case, the physician should establish during the first visit with the surrogate and the commissioner(s) an understanding that the care of the surrogate is the physician's only responsibility, that the surrogate will determine the level of involvement of the commissioner(s) during the pregnancy and that the surrogate's prenatal health care proceeds according to her wishes. Moving through the pregnancy, the health care provider should carefully monitor the surrogate to detect any obstetric and psychological complications. Social work, ethical or legal support should become involved at the first hint of difficulty. Most of the time, a happy family will be created, and everyone involved will have had a positive experience.
This article has been peer reviewed.

From the Department of Obstetrics and Gynecology, McMaster University, Hamilton, Ont.

Competing interests: None declared.

\section{REFERENCES}

I. Rivard G, Hunter J. The law of assisted human reproduction. Markham (ON): LexisNexis Canada Inc; 2005.

2. Shalev C. Birth power: the case for surrogacy. New Haven (CT): Yale University Press; 1989.

3. McLachlan HV, Swales JK. Babies, child bearers and commodification: Anderson, Brazier et al., and the political economy of commercial surrogate motherhood. Health Care Anal 2000;8:1-18

4. Van Zyl L. Intentional parenthood: responsibilities in surrogate motherhood. Health Care Anal 2002;10:165-75.

5. Campbell AV. Surrogacy, rights and duties: a partial commentary. Health Care Anal 2000;8:35-40.

6. Harris J. The welfare of the child. Health Care Anal 2000;8:27-34

7. Ber R. Ethical issues in gestational surrogacy. Theor Med Bioeth 2000;21:153-69.

8. Anderson ES. Why commercial surrogate motherhood unethically commodifies women and children: reply to McLachlan and Swales. Health Care Anal 2000;8:19-26.

9. Royal Commission on New Reproductive Technologies. Proceed with care: final report of the Royal Commission on New Reproductive Technologies. Ottawa: Canadian Government Publishing; 1993.

Io. Brinsden PR. Gestational surrogacy. Hum Reprod Update 2003;9:483-91.

II. Kluge EHW. Readings on biomedical ethics: a Canadian focus. Scarborough (ON): Prentice Hall Canada; I995.

I2. Procureur général du Québec [requerant] c. Procureur général du Canada [intime], Cour d'appel du Québec, no 500-09-015177-04I CA. Renvoi à la Cour d'appel du Québec relatif à la Loi sur la procréation assistée (L.C. 2004, ch. 2).

I3. Assisted Human Reproduction Act, SC 2004, c.2.

I4. Filiation of children born of assisted procreation (I99I) RSQ.c C-I-I, s 54I.

I5. Tremblayv. Daigle (I989), SCR.

I6. Rv. Drummond (I996), (Ont Ct (Prov Div))

I7. Cotton K. Surrogacy should pay. BMJ 2000;320:928-9.

I8. Corson SL, Kelly M, Braveman AM, et al. Gestational carrier pregnancy. Fertil Steri I998;69:670-4.

I9. Utian WH, Goldfarb JM, Kiwi R, et al. Preliminary experience with in vitro fertilization surrogate gestational pregnancy. Fertil Steril rg89;52:633-8.

20. Marrs RP, Ringler GE, Vargyas JM, et al. The use of surrogate gestational carriers for assisted reproductive technologies. Am J Obstet Gynecol I993;I68:1858-63.

2I. Soderstrom-Anttila V, Blomqvist T, Foudila T, et al. Experience of in vitro fertilization surrogacy in Finland. Acta Obstet Gynecol Scand 2002;81:747-52.

22. Parkinson J, Tran C, Tan T, et al. Perinatal outcome after in-vitro fertilization-surrogacy. Hum Reprod I999; I4:67I-6.

23. Duffy DA, Nulsen JC, Maier DB, et al. Obstetrical complications in gestational carrier pregnancies. Fertil Steril 2005;83:749-54.

24. Reame NE. The surrogate mother as a high risk obstetrical patient. Womens Health Issues I991; I:15I-4.

25. Lester EP. A surrogate carries a fertilized ovum: multiple crossings in ego boundaries. Int J Psychoanal 1995;76:325-34.

26. Jessee SS. Panel report infertility, surrogacy and the new reproductive techniques: psychoanalytic perspectives. Int J Psychoanal I996;77:129-33

27. Schwartz LL. A nightmare for King Solomon: the new reproductive technologies. $J$ Fam Psychol 2003;17:229-37.

28. Fischer S, Gillman I. Surrogate motherhood: attachment, attitudes and social support. Psychiatry I99I;54:13-20.

29. Blyth E. I wanted to be interesting. I wanted to be able to say 'I've done something interesting with my live': Interviews with surrogate mothers in Britain. J Reprod Infert Psychol 1994:189-98.

30. Kleinpeter CB. Surrogacy: the parents' story. Psychol Rep 2002;9I:20I-I9.

3I. MacCallum F, Lycett E, Murray C, et al. Surrogacy: the experience of commissioning couples. Hum Reprod 2003; 18:1334-42.

32. Jadva V, Murray C, Lycett E, et al. Surrogacy: the experiences of surrogate mothers. Hum Reprod 2003;18:2196-204.

Correspondence to: Dr. Dan R. Reilly, 205 Queen St. E, Fergus ON NIM IT2; fax 519 787-7421; dreilly@mcmaster.ca 